\title{
Maiores bancos privados no Brasil: um perfil econômico e sociopolítico ${ }^{1}$
}

ARY CESAR MINELLA*

\section{Introdução}

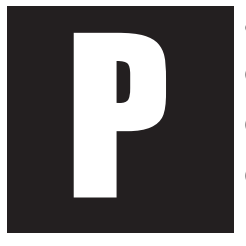

ara se avaliarem as dimensões da riqueza, parece imprescindível considerar-se o papel que o sistema financeiro tem desempenhado no Brasil. Com um grau relativamente alto de concentração das operações financeiras em algumas poucas instituições estatais e privadas, o sistema bancário adaptou-se, nos últimos 15 anos, aos diversos contextos econômicos e políticos de maneira a assegurar expressiva lucratividade. Em períodos de inflação alta, os chamados ganhos inflacionários adquiriram grande importância. Altas taxas de juros nas operações de crédito e grande volume de aplicação em títulos públicos constituem componentes fundamentais, além de haver grande diferença entre as taxas cobradas e aquelas pagas pelas instituições financeiras (o chamado spread bancário). As tendências recentes sinalizam para um maior crescimento relativo do crédito pessoal e do crédito ao consumo, caracterizados por altíssimas taxas de juros, e para o

\footnotetext{
* Professor Titular da UFSC - Pesquisador CNPq. Brasil.

1 Trabalho vinculado ao projeto de pesquisa América Latina: uma visão sociopolítica das transformações e das perspectivas do sistema financeiro (III etapa), realizado com apoio do CNPq (versão atualizada de trabalho apresentado no Congresso da Associação Latino-americana de Ciência Política, Campinas, 2006).
} 
incremento dos ganhos com a cobrança de tarifas bancárias. Todo esse processo realiza-se no contexto de uma reestruturação do trabalho no setor, ocorrida especialmente a partir de meados dos anos 1990. Se não parece haver dúvidas de que o setor financeiro tem sido um dos grandes (se não o maior) beneficiados pelas conjunturas econômicas e pelas políticas econômicas adotadas nos últimos anos (incluindo o atual governo), o que parece intrigante é que essa situação se sustente e se legitime, mantendo uma ordem social, econômica e política especialmente benéfica a um segmento específico da sociedade capitalista vigente no País (LEILA, 2005; GRÜN, 2004).

Estamos em um momento do capitalismo caracterizado por uma preponderância da acumulação financeira (CHESNAIS, 2003), alicerçada numa dimensão especulativa sem precedentes, que permite, mediante diversos mecanismos e inovações financeiras, a renovação do grau de endividamento (das famílias, das empresas, dos governos) e a realização de operações de toda ordem ao redor do globo de forma instantânea. Essa acumulação torna-se viável no contexto de uma reestruturação produtiva do capitalismo que tem imposto maior precarização do mundo do trabalho, significativas mudanças previdenciárias, terceirização, redução do número de trabalhadores bancários e fragilização da organização sindical pela combinação de novas e antigas formas de exploração, pela apropriação da renda dos assalariados via crédito ao consumo e serviços financeiro, e pela apropriação fiscal através da dívida pública.

Nessa conjuntura, a análise do sistema financeiro, de suas instituições - privadas e estatais - e das complexas relações nas quais estão inseridos é um grande desafio. Apresento uma contribuição, mínima por certo, mas que tenta trazer para o debate algumas considerações e dados, sistematizados de forma a permitir uma perspectiva sociopolítica da questão.

Tendo presentes esses aspectos mais gerais, é necessário analisar o sistema financeiro e suas instituições inseridos em um amplo contexto de 
poder das instituições financeiras no capitalismo contemporâneo. Na impossibilidade de analisar todas as dimensões da questão, destaco os seguintes aspectos: a) o controle sobre o fluxo de capitais; b) a existência dos conglomerados e grupos financeiros; c) a estrutura e dinâmica da representação de classe do setor; d) a participação no processo político e nos aparatos de decisão do Estado. Tomando como referência o ano de 2005, elaborei um perfil econômico e especialmente sociopolítico das dez maiores instituições financeiras privadas atuantes no Brasil, como forma de entender melhor a situação dos bancos no País e o espaço privilegiado que ocupam hoje na acumulação de capital e na esfera política.

\section{Controle sobre o fluxo de capitais e hegemonia financeira}

Um dos fatores fundamentais que permitem o poder dos bancos e das instituições financeiras é o controle que estes exercem sobre parte substantiva dos recursos e do fluxo de capitais na economia. Esse controle possibilita, em determinadas circunstâncias, criar constrangimentos ao processo decisório das políticas governamentais e às decisões estratégicas das empresas, caracterizando-se um processo que alguns autores identificam como hegemonia financeira (MINTZ; SCHWARTZ, 1985). As instituições financeiras, e aqui estão incluídos os investidores institucionais, ao controlarem um fluxo significativo de capitais, possuem a capacidade de definir algumas linhas gerais da economia nas quais as corporações não-financeiras operam, uma vez que podem impulsionar o desenvolvimento de certas áreas em detrimento de outras e também restringir o compromisso com um determinado setor, empresa ou país.

O exercício dessa hegemonia, no entanto, é algo problemático, pois está inserido em diferentes conjunturas econômicas (e políticas) e em contextos regionais. Nos períodos críticos, quando a disponibilidade de capitais 
diminui, esse poder hegemônico faz-se sentir mais claramente. Países e empresas em condições de alto endividamento, necessitando renovar urgentemente seus créditos, estão submetidos, de forma mais intensa, aos constrangimentos dessas instituições financeiras, incluída aqui, no caso dos países, a ação de organismos financeiros como o Fundo Monetário Internacional e o Banco Mundial. A possibilidade de impor constrangimentos aos processos decisórios das empresas e dos governos condiciona-se às condições diferentes do ciclo econômico, à capacidade de autofinanciamento das empresas, ao grau de desenvolvimento do mercado de capitais, à possibilidade de existirem alternativas de crédito, ao grau de concentração da oferta de crédito e às condições gerais de endividamento das empresas e governos.

Um dos aspectos mais importantes a serem destacados é a grande concentração dos recursos em algumas poucas instituições. No caso brasileiro, existe atualmente uma clara divisão entre algumas instituições de controle estatal (especialmente Banco do Brasil e Caixa Econômica Federal) e alguns bancos privados nacionais e estrangeiros (MINELLA; FERREIRA, 2006; MAKLER; NESS, 2002). Esse grau de concentração de recursos em poucas mãos gera não apenas poder econômico, porque envolve um gigantesco fluxo de capital, mas também interesse político na definição das políticas macroeconômicas que possam afetar esse universo. Como resultado global, os controladores de um número reduzido de instituições financeiras exercem influência sobre o mundo empresarial e o governamental muito além daquela exercida por outras forças sociais, incluindo-se os segmentos empresariais.

\section{Grupos econômicos}

O segundo aspecto a ser considerado é a existência de grupos econômicos que, embora constituam um fenômeno bastante amplo e central no capitalismo contemporâneo, têm recebido uma atenção ainda insuficiente 
por parte das Ciências Sociais (GRANOVETTER, 1994; GONÇALVES, 1991).² A partir dos anos 1990, o interesse pelo tema foi ampliado, haja vista vários estudos empíricos e discussões teóricas publicadas na América Latina (e.g. COMIN et al., 1994; ALCORTA, 1992; PORTUGAL JUNIOR, 1994; STOLOVICH, 1993, 1995; SCHVARZER, 1995; AZPIAZU; BASUALDO; KHAVISSE, 1989; BASUALDO, 2002). No caso brasileiro, a retomada de estudos sobre os grupos econômicos leva a uma melhor compreensão da dinâmica econômica e política no período (COMIN et al., 1994).

Embora existam algumas divergências conceituais e dificuldades operacionais nos procedimentos empíricos de análise, em termos gerais, têm-se destacado dois aspectos. Primeiro, a importância dos grupos, tanto como agentes privilegiados das operações econômicas em esfera global, quanto por sua influência ou potencial de influência direta e indireta sobre as políticas governamentais. O segundo aspecto refere-se a seu papel no mundo do entretenimento e da cultura, constituindo-se em grandes artífices da cultura mundial no final do século XX (ORTIZ, 1994, p.147-182).

Um grupo econômico pode ser definido como um

[...] conjunto de empresas que, ainda que juridicamente independentes entre si, estão interligadas, seja por relações contratuais, seja pelo capital, e cuja propriedade (de ativos específicos e, principalmente, do capital) pertence a indivíduos ou instituições, que exercem o controle efetivo sobre este conjunto de empresas. (GONÇALVES, 1991, p. 494).

Assim, o grupo econômico expressa relações de força e de poder, em torno das quais se movimentam indivíduos, classes, grupos sociais de um modo geral, formando redes de solidariedade e campos de conflito que en-

2 O fenômeno recebe diferentes denominações: grupo econômico (América Latina); Zaibatsu, depois keiretsu (Japão); Chaebol (Coréia do Sul); twenty-two families (Paquistão); Indian business house (Índia); Business Group (Inglaterra) (GRANOVETTER, 1994). 
volvem acionistas, gerentes e trabalhadores (PORTUGAL JUNIOR, 1994, p. 17). Considera-se, nesses termos, o grupo econômico como um lócus de acumulação de capital e um lócus de poder (GONÇALVES, 1991, p. 494).

Existe uma ampla variedade de grupos econômicos, que se caracterizam por diferentes tipos de propriedade: alguns são controlados por indivíduos, por uma família ou por um conjunto de famílias relacionadas de forma direta ou indireta; outros podem ser mantidos de forma indireta mediante sucessivas participações acionárias ou por meio de holdings. Como sugere Granovetter (1994), acordos e participações acionárias cruzadas podem ganhar uma estrutura extremamente complexa, envolvendo várias empresas, articuladas por redes de diretorias cruzadas.

A relação entre as políticas governamentais e os grupos econômicos envolve muitos aspectos, tais como regulamentação e desregulamentação, políticas antitrustes, estatização, políticas industriais e tecnológicas, formas de financiamento do Estado, regulação e controle da força de trabalho (GONÇALVES, 1991, p. 494). Logo, a relação dos grupos econômicos com o Estado merece toda a atenção, não apenas para o entendimento dos problemas de poder e das políticas públicas, mas também para a análise das formas, características e comportamento que os grupos assumem. A questão da organização e configuração dos grupos econômicos depende tanto de fatores econômicos, como da interação de fatores políticos e socioculturais. Seu poder sobre os mercados e a sociedade em geral e sua capacidade de instituir valores, de se transformar assim em um instrumento político e de controlar substantivos fluxos de capitais garantem-Ihes condições de vetar decisões de regulação pública, relativizar o poder do Estado e afetar a economia de diversos países (PORTUGAL JUNIOR, 1994, p. 55-56). Os bancos que atuam no Brasil não são diferentes. Eles estão inseridos, ou mesmo o constituem, no núcleo central de grupos econômicos cujo papel é determinante em questões econômicas e políticas da maior relevância. 


\section{Estrutura e dinâmica da representação de classe}

$\mathrm{Na}$ análise do poder das instituições financeiras, é importante levarem-se em consideração algumas dimensões de sua organização de classe, como, por exemplo, as associações de bancos e de outras instituições financeiras existentes nos países capitalistas avançados e também na América Latina, cuja expressão formal maior, no caso dos bancos, é a Federação Latino-Americana de Bancos (FELABAN). O processo de internacionalização do sistema financeiro na América Latina se expressa ainda pela significativa presença de instituições estrangeiras nas direções dos órgãos de representação de classe em muitos países, incluindo o Brasil, destacando-se grandes grupos internacionais dos Estados Unidos e da Europa. Citibank (Citigroup), Banco Bilbao Vizcaya Argentaria (BBVA) e o Banco Santander Central Hispânico (BSCH) constituem os exemplos mais significativos. Em 2000 e em 2006, cada um deles atuava de forma simultânea em associações de classe do setor financeiro em sete países. No caso do Citibank, a atuação se estendia a 11 associações, das quais cinco eram do Brasil.

Os dados apresentados reforçam a hipótese da formação do que se denominou redes transassociativas, interpretadas como redes que se formam a partir da participação simultânea de uma mesma empresa ou grupo econômico - no nosso caso, uma instituição, um conglomerado ou um grupo financeiro - em várias associações de classe, em diferentes países. Poderíamos assim falar de uma rede transassociativa no sistema financeiro e da possibilidade de uma atuação articulada desses grupos na busca de definição de estratégias comuns para as Associações de Bancos na América Latina. O significado dessas redes pode ser interpretado de várias formas: a) indica e reforça assimetrias de poder corporativo no sistema financeiro internacional; b) expande a possibilidade de posicionamentos e atuações coordenadas na América Latina; c) cria um canal privilegiado de fluxo de informação especialmente para as grandes instituições financeiras internacio- 
nais. Além disso, por meio das associações de classe local, os bancos estrangeiros internalizam seus interesses e ganham representatividade nas negociações com o governo e com outros segmentos empresariais (MINELLA, 2003, 2005).

No caso brasileiro, a estrutura de representação de classe conta com várias associações, que articulam os interesses dos vários segmentos do sistema financeiro, a maior parte delas formalmente centralizadas na Confederação Nacional das Instituições Financeiras (CNF). Em relação aos banCos, ganha destaque a FEBRABAN (Federação Brasileira de Bancos) (MIRANDA, 2004). A Associação Brasileira de Bancos (ABBC) representa os pequenos e médios bancos. Existe também uma associação que agrega os bancos estrangeiros que atuam no País (Associação de Bancos Brasileiros Internacionais - $\mathrm{ABBI})$. Entre outras entidades, podemos mencionar a ANDIMA (Associação Nacional das Instituições do Mercado Aberto) e a ANBID (Associação Nacional dos Bancos de Investimento) (MINELLA, 2005).

\section{Participação no processo político e nos aparatos de decisão do Estado}

A análise das relações que se estabelecem entre o Estado e o sistema financeiro é um grande desafio para a compreensão da dinâmica capitalista contemporânea. No Brasil, as conexões e os interesses que se instituem a partir da dívida pública constituem um traço fundamental dessa relação. Além disso, a centralidade que as decisões e ações do Banco Central passaram a ter para a política econômica transformou-o em instituição estratégica para a manutenção da hegemonia financeira, portanto essencial para os interesses do empresariado financeiro no País. A existência de presidentes e diretores do Banco Central vinculados ao universo dos bancos privados materializa uma das expressões dessa relação. 
Ao mesmo tempo, o novo papel que o poder legislativo passou a assumir após a democratização política recebeu atenção do sistema financeiro, e o financiamento eleitoral representa apenas um dos indicadores do interesse que o setor demonstra pelo processo político. ${ }^{3}$ Cientes de que se trata de uma delimitação bastante pontual, embora fundamental, para captar dimensões da relação Estado-Sistema Financeiro, tratarei de utilizar os indicadores mencionados na avaliação do perfil sociopolítico dos dez maiores bancos privados do País.

\section{Perfil econômico e sociopolítico dos dez maiores bancos privados que atuam no Brasil}

A reestruturação do sistema bancário ocorrida no Brasil, principalmente a partir de meados dos anos 1990, tem sido amplamente analisada, especialmente pela literatura econômica. Entre as características dessa reestruturação, podemos destacar as seguintes (MINELLA; FERREIRA, 2006): a) o processo de centralização-concentração bancária que se acelerou no período e concentrou as operações financeiras em um número reduzido de instituições privadas e estatais (ROCHA, 2001; VIDOTTO, 2002; CARVALHO et .al., 2002; PAULA; MARQUES, 2004; JACOB, 2003; CINTRA, 2006); a partir de dados do Banco Central, é possível se constatar que, em 2005, treze bancos - três federais e dez privados - controlavam 83,29\% das operações de crédito e arrendamento mercantil de todo o sistema financeiro nacional; b) a abertura financeira, que levou ao aumento da presença no País de instituições e conglomerados financeiros internacionais (FREITAS; PRATES, 2001; VIDOTTO, 2002; CINTRA, 2006; CINTRA et al., 2001; PASSOS, 2001; SICSÚ, 2006); c) o processo de privatização dos

3 Uma interessante análise sobre a reconfiguração do espaço financeiro brasileiro e de sua relação com a cena política, a partir de uma sociologia das finanças, é desenvolvida por Grün (2004). 
bancos estaduais (VIDOTTO, 2002; PAULA; MARQUES, 2004; FERREIRA; ALVIM, 2001; SALVIANO Jr., 2004); d) a reestruturação do trabalho bancário (JINKINGS, 2002; JUNCKES, 2004; DRUCK et al., 2002; LARANJEIRA; FERREIRA, 2000; GRISCI, 2002; RODRIGUES, 2004).

Tendo presente essa reestruturação, abordarei a seguir um conjunto de indicadores que situam as maiores instituições financeiras privadas em um contexto mais amplo de relações econômicas e, especialmente, sociopolíticas. Foram selecionados os dez maiores bancos privados, segundo o volume das operações de crédito em dezembro de 2005, conforme dados do Banco Central do Brasil (2006): Bradesco, Itaú, ABN Amro, Unibanco, Santander, HSBC, Citibank, Safra, Votorantim e BankBoston. Em conjunto, esses bancos controlaram, em 2005, 48,65\% do volume total das operações de crédito e 32,55\% dos títulos e valores mobiliários de todo o sistema financeiro (cf. Quadro 1). Quatro são bancos privados nacionais, um é classificado como associado ao capital externo (Unibanco) e os demais constituem grandes instituições financeiras estrangeiras, ou seja, entre os dez maiores bancos privados do País, cinco são estrangeiros.

Para definir o perfil dos maiores bancos privados do País, utilizei as seguintes características e indicadores: 1) constituição de grupo econômico ou financeiro caracterizado pelo controle não apenas do banco e de outras instituições financeiras - o que configuraria um conglomerado financeiro , mas também de empresas que atuam no setor não-financeiro; 2) participação acionária em empresas de outros setores, que não são controladas pelo grupo; 3) controle sobre a dívida pública interna, tomando como indicador o volume de ativos em títulos e valores mobiliários; 4) participação no processo de privatização dos bancos estaduais; 5) envolvimento com a representação de classe do setor financeiro - o indicador utilizado é a presença dos bancos na diretoria das associações de classe no Brasil e na América Latina; 6) ocupação de cargos estratégicos de decisão no aparato estatal, 
cujo indicador será o trânsito de pessoas entre instituições financeiras privadas e a direção do Banco Central do Brasil, especialmente a partir de meados dos anos 1990; 7) atuação no processo político mediante o financiamento das campanhas eleitorais; 8) vinculação com organizações políticoideológicas, como os institutos liberais.

Por problema de espaço, não foram incluídos, na análise, outros indicadores de importância inegável, quais sejam: a) a participação dos bancos selecionados na dívida externa, enquanto credores do governo e das empresas privadas estabelecidas no País; e b) os vínculos com os meios de comunicação e a atuação na esfera cultural, especialmente por meio de fundações específicas. O levantamento de dados não alcançou a mesma extensão para todos os indicadores, de forma que algumas observações terão ainda um caráter indicativo. Os resultados alcançados serão comentados a seguir e estão sintetizados no Quadro 1.

\section{Os grupos econômicos e outras participações acionárias}

Procuro verificar em que medida os bancos constituem ou integram grupos econômicos ou grupos financeiros que se transformam em lócus de poder econômico e também político, como indica a literatura mencionada anteriormente. Esse quadro mais amplo permite melhor avaliarem-se as instituições financeiras e seu poder na atual fase do capitalismo no País. Um estudo sobre a origem do capital bancário no Brasil constatou que os grandes bancos brasileiros

[...] faziam parte de grupos que contavam com dezenas de empresas, não só da área financeira, mas também de outros ramos de atividade [...] tais empresas - não eram propriedades diretas dos bancos, mas tinham ou o controle acionário detido por famílias de banqueiros, ou participações ou relações de interesse com os bancos. (COSTA, 2002, p. 21). 
Os quatro maiores bancos privados nacionais (Bradesco, Itaú, Safra e Votorantim) e o banco classificado como associado ao capital estrangeiro (Unibanco) estão integrados a grupos econômicos que controlam o capital acionário de empresas não-financeiras de diversos ramos e/ou dele participam. Destacam-se especialmente três deles (Bradesco, Itaú e Votorantim), inseridos entre os quinze maiores grupos privados do País (segundo VALOR GRANDES GRUPOS, 2005).

Em 2000, o Bradesco criou a Bradespar, que passou a abrigar as empresas controladas fora do setor financeiro, e manteve importantes participações acionárias em outras empresas, como a Usiminas, Petrobrás, Perdigão e Gerdau (VALOR, 23 de maio de 2005, p. C1). Segundo Costa (2002, p. 21), o Bradesco investia parcelas ponderáveis das reservas técnicas da seguradora e da previdência privada em participações minoritárias em empresas, especialmente industriais, buscando condições que lhe permitissem ocupar um assento no conselho de administração. Isso Ihe garantia uma participação em 41 companhias não-financeiras, no valor de cerca de US $\$ 1,5$ bilhão. ${ }^{4}$

No período em análise, a holding Itaúsa (grupo Itaú) controlava empresas dos ramos de madeira, móveis, papel, informática, química e petroquímica, algumas das quais estão entre as maiores de seus respectivos ramos. O Banco Safra faz parte de uma rede internacional de empresas controladas pela família Safra ou nas quais esta tem participação acionária, compreendendo atividades bancárias, de telecomunicações, de produção de papel e celulose e de pecuária. O Banco Votorantim está inserido em um dos maiores grupos industriais do país, cujas atividades incluem metalurgia, siderurgia, papel, celulose, química, petroquímica, materiais de cons-

\footnotetext{
4 A legislação brasileira não permite empréstimos a companhias nas quais o banco detenha mais de $10 \%$ do capital. Haveria, entretanto, uma vantagem na estratégia de participação abaixo desse percentual: manter a empresa como cliente do banco (COSTA, 2002, p. 21).
} 
trução e decoração, energia elétrica, alimentos e agricultura (VALOR GRANDES GRUPOS, 2005, p.252-255). O Unibanco é controlado pela Unibanco Holding, que, por sua vez, é controlada pela família Moreira Salles por meio da E. Johnston Representação e Participação. O Grupo Moreira Salles é constituído por uma intrincada rede de empresas controladas e coligadas, com uma diversificada participação de capital estrangeiro. Uma análise mais detalhada das participações desse grupo no setor não-financeiro deveria rastrear as empresas de participação, especialmente a E. Johnston. ${ }^{5}$ Entre os exemplos dessa participação, podemos mencionar a Blockbuster Vídeo, a maior rede de videolocadora do Brasil, que vincula o Grupo Moreira Salles ao Grupo Viacom, um dos maiores do mundo em entretenimento, e os investimentos do grupo no setor de mineração, como a Companhia Brasileira de Metalurgia e Mineração (CBMM). Esta é a maior produtora mundial de Nióbio (o grupo Moreira Salles controla 55\% da empresa), tem subsidiárias na Europa (Niobium Products Company $\mathrm{GmbH}$ ), na América do Norte (Reference Metals Company Inc., Pittsburg) e na Ásia (a CMMM Ásia Co. Ltd., Tóquio) e conta ainda com a participação de uma subsidiária da Unocal Corporation e da Unipar - União das indústrias Petroquímicas S.A. (ARAÚJO, 2003, p. 24).

Podemos concluir que, pelo menos em cinco casos (Bradesco, Itaú, Votorantim, Safra e Unibanco-Moreira Salles), existe, de formas direta ou indireta, com intensidade variada, uma diversificada rede de interesses acionários que implicam controle e participação em empresas não-financeiras. Os cinco bancos estrangeiros (ABN Amro, Santander, HSBC, BankBoston

5 O Unibanco está inserido numa cadeia de participações (as informações referem-se ao começo de 2002). A família Moreira Salles (Fernando, João, Pedro e Walter Jr.) controla, em partes iguais, a E. Johnston Participações Ltda, que detém 85,52\% da E. Johnston Repres. e Part. S.A, que controla $66,72 \%$ da Unibanco Holding, que conta com participação do capital estrangeiro (Caixa Brasil SGPS, de Portugal, com 10\%, Commerzbank Aktiengesellschaft, da Alemanha, com 8,98\% e The Daí-Ichi Kangyo Bank, do Japão, com 6,16\% - totalizando 25,14\%). É essa holding que controla (96,59\%) o Unibanco - União de Bancos Brasileiros (Cf. UNIBANCO, 2002, p.105). 
e Citibank) estão entre as maiores instituições financeiras do mundo, atuando em vários países, algumas delas integradas a grupos financeiros com ramificações de controle ou participação acionária em empresas de diversos ramos, como é o caso do Citigroup, que controla o Citibank, e do Santander, ao qual se integram acionistas de diversificados ramos da economia espanhola.

\section{Controle sobre a dívida pública}

O montante de ativos que os bancos direcionam para o mercado de títulos públicos tem como indicador o volume de ativos em títulos e valores mobiliários, compostos majoritariamente de títulos públicos federais. Em 2005, os 10 bancos privados selecionados para esta pesquisa controlavam $32,55 \%$ dessa rubrica, enquanto apenas duas instituições federais (Banco do Brasil e Caixa Econômica Federal) eram responsáveis por 35,92\%. ${ }^{6}$ Isso indica que a dívida pública está concentrada na carteira de alguns grandes bancos (estatais e privados) e se tornou uma importante fonte de lucro dessas instituições. Além disso, constitui um fator favorável aos bancos para o constrangimento das decisões estratégicas de política econômica (FERREIRA, 2005).

\section{Privatização e os grandes bancos privados}

O processo de privatização dos bancos estaduais favoreceu particularmente dois grandes bancos privados nacionais e dois bancos estrangeiros.

\footnotetext{
6 Os dados do Banco Central para o ano de 2005 incluem, nessa rubrica, instrumentos financeiros derivativos, o que dificulta uma análise mais precisa. No ano de 2000, os dez maiores bancos privados (naquele ano, incluía-se na lista o Sudameris e não o Banco Votorantim) controlavam 44,7\% do total de títulos e valores mobiliários do sistema bancário. Os bancos privados parecem ter diminuído sua participação nessa rubrica a favor dos bancos estatais e incrementado sua participação no volume das operações de crédito. ]
} 
Para o controle do Bradesco, passaram cinco bancos: o Banco do Estado da Bahia (Baneb), em 1999, o Credireal de Minas Gerais, em 1997, e bancos estaduais federalizados, como o Banco do Estado da Amazônia (Bea), em 2002, o Banco do Estado do Maranhão (Bem), em 2004, e o Banco do Estado do Ceará (BEC), em 2005. O Itaú incorporou quatro instituições: o Banco do Estado do Rio de Janeiro (Banerj), 7 em 1997, o Banco do Estado de Minas Gerais (Bemge), em 1998, o Banco do Estado do Paraná (Banestado), em 2000, e, no ano seguinte, o Banco do Estado de Goiás (Beg), instituição federalizada em 1999. Para o controle de instituições estrangeiras, passaram o Banco do Estado de Pernambuco (Bandepe), incorporado pelo ABN Amro em 1998, e o Banespa, que se encontrava sob controle do governo federal e foi adquirido em 2000 pelo espanhol Santander (em cuja conta deve ser incluído, a partir de 1997, também o Meridional, banco federal que fora adquirido anteriormente pelo Banco Bozano-Simonsen).

\section{Banco Central e os bancos privados}

As relações entre o setor financeiro e o Banco Central do Brasil têm suscitado várias análises na literatura. Uma das dimensões da questão é a presença de membros na direção do Banco (presidente e diretores) provenientes diretamente de instituições financeiras privadas, e, num movimento inverso, a ida de membros da direção, ao deixarem o Banco Central, para os bancos privados ou a constituição, por esses membros, de empresas financeiras próprias (NEIVA, 1995; FERREIRA, 2005, p. 96-100; CARVALHO, 2005). É emblemática a indicação de alguns nomes para a presidência do Banco Central. Em 1985, o Presidente José Sarney indicou um

7 O Banerj foi liquidado em 1996, e seus ativos podres foram socializados, enquanto uma distribuidora do grupo deu origem ao banco saneado, que foi incorporado pelo Itaú em 1997 (VIDOTTO, 2002, p. 241). 
banqueiro que dirigia a Associação Brasileira de Bancos Comerciais (ABBC, hoje denominada Associação Brasileira de Bancos). Um dos presidentes do Banco Central durante o governo Cardoso proveio do universo financeiro internacional, característica que se mantém no governo Lula. Análises sobre a origem profissional de diretores do Banco Central ao longo dos anos 1990 constataram que um número significativo deles possuía carreira em instituições privadas e carreiras mistas, que associavam atividades em empresas privadas com carreiras burocráticas e acadêmicas (OLIVIERI, 2001; NOVELLI 2001; MORAIS, 2005).

Em relação aos dez maiores bancos privados, podemos constatar que dois deles se destacam nesse trânsito privado-público, considerando-se a última década do século XX e o início do século XXI. Circularam pelo grupo Itaú pelo menos seis membros da diretoria do Banco Central e, pelo Unibanco, sete. Ao BankBoston esteve vinculado o presidente do Banco Central a partir de 2003 e, recentemente, dois diretores do Banco Central relacionam-se com o ABN Amro. ${ }^{8}$

Em junho de 1996, formou-se o Comitê de Política Monetária (Copom), com a função de definir as diretrizes da política monetária e a taxa de juros.

8 Segundo dados preliminares, passaram para o grupo Itaú: Pérsio Arida, presidente do BC entre 11/01/95 e 13/06/95; Gustavo Loyola, presidente do BC de 13/11/92 a 29/03/93 e de 13/06/95 a 20/ 08/97; Fernão Bracher, presidente do BC entre 28/08/85 e 11/02/87; Tereza Grossi, Diretora de Fiscalização de 30/03/00 a 14/03/03; Sérgio Werlang, diretor na gestão de Armínio Fraga; Sérgio de Freitas, diretor entre março/abril de 1985. Vínculos anteriores ou posteriores com o Unibanco: Pedro Malan, presidente do BC de 09/09/93 a 31/12/94; Armínio Fraga Neto, presidente do BC de 04/03/ 99 a 01/01/03 (também Conselheiro Internacional do JP Morgan Chase); Daniel Gleizer, diretor do BC de 04/03/99 a 21/01/02; Francisco Gros, presidente do BC ao final do Governo Collor; Armin Lore, diretor no período 1988-90; Alexandre Schwartsman, economista-chefe do Unibanco, que assumiu uma diretoria do BC em 2003 e, posteriormente, passou para o ABN Amro; na segunda metade dos anos 90, Demósthenes Pinho Neto foi economista-chefe do Unibanco e depois ocupou a diretoria internacional do Banco Central. Pedro Malan assumiu a presidência do Conselho de Administração do Unibanco em maio de 2004. Vínculos com o ABN Amro: Mario Carvalho Mesquita, economista-chefe para América Latina deste banco, assumiu a Diretoria de Estudos Especiais do BC em junho de 2006; Schwartsman, já mencionado, saiu do BC para assumir a função de Mesquita nesse banco privado. Vínculos anteriores com o BankBoston: Henrique Meirelles, presidente do BC a partir de 2003 (FERREIRA, 2005, p. 99; OLIVIERI, 2001; UNIBANCO, 2004). 
Constituído pelo presidente e alguns diretores do Banco Central (total de oito membros), o Copom ganhou maior importância a partir de junho de 1999, com a adoção governamental da sistemática de metas para a inflação. As decisões do Comitê afetam o sistema financeiro, a economia em geral e, particularmente, a dívida pública, já que grande parte desta está indexada pela taxa de juros Selic, definida pelo Comitê.

\section{Os dez maiores e o processo político: o financiamento das campanhas eleitorais}

As instituições financeiras têm-se destacado no financiamento das campanhas eleitorais, especialmente para o executivo federal. Como é do conhecimento de todos, os recursos formalmente declarados pelos partidos não representam necessariamente o gasto total da campanha, mas permitem identificar, pelo menos parcialmente, a origem do financiamento. Bancos e empresas dos grupos financeiros estiveram entre os principais financiadores das campanhas para o Congresso e para a Presidência da República em 1994, 1998 e 2002. Na lista dos dez maiores bancos, pelo menos cinco abriram seus cofres para o financiamento eleitoral: Bradesco, Itaú, Unibanco, Santander, Votorantim e ABN Amro.

\section{Bancos e organizações político-ideológicas}

A participação na estrutura de representação de classe do sistema financeiro no Brasil é uma característica marcante de oito dos dez maiores bancos. Em 2006, oito deles, incluindo quatro estrangeiros, integravam a diretoria da Federação Brasileira de Bancos (FEBRABAN). Ademais, seis deles atuavam também em associações de classe de outros países latinoamericanos. Além do Brasil, o Citibank atuava em outros nove países, o 
Santander em seis, o BankBoston em três, o ABN Amro em dois e o Itaú e o HSBC em mais um país.

Ao lado das estruturas sindical, associativa e partidária, os empresários ou a burguesia financeira também valem-se de um conjunto de organizações de natureza diversa para articularem seus interesses. Tomamos como exemplo os institutos liberais, constituídos no Brasil como entidades civis por um grupo de grandes empresários, no início dos anos 80, centrados na difusão da doutrina neoliberal, especialmente como fundamento de políticas públicas (GROS, 2003b, p. 275). Mantidos por grandes grupos econômicos nacionais e estrangeiros que operam no País, os institutos estão inseridos em uma rede mundial que inclui intelectuais, acadêmicos, políticos, institutos de pesquisa, publicações liberais e da mídia, em especial nos Estados Unidos e na Grã-Bretanha. (ibid., p. 275-276). Vinculados a uma rede internacional de think tanks, os institutos desenvolveram uma série de ações durante os anos 90 (cf. especialmente GROS, 2003b e GROS 2003a para os anos 80). No Brasil, seis dos dez bancos de nossa lista estiveram vinculados de alguma forma aos institutos liberais. Mais recentemente, o Instituto de Estudos de Política Econômica, sediado no Rio de Janeiro, constitui um importante grupo de pesquisadores, do qual participam também economistas e empresários vinculados ao sistema financeiro, que desenvolve e propõe políticas de cunho liberal.

\section{Considerações finais}

As variáveis consideradas e os dados levantados permitem observar que, em seu conjunto, os dez maiores bancos privados representam muito mais que intermediários financeiros que controlam um volume expressivo do crédito (caro e reduzido, em parâmetros comparativos com outros países capitalistas) e parte significativa dos títulos e valores mobiliários, onde 
estão situados os títulos governamentais, portanto a dívida pública interna. No limite das informações coletadas, pelo menos sete deles estendem seus interesses a uma variada gama de empresas não-financeiras. O exame dessa intrincada rede de controle e participações acionárias coloca-se como uma necessidade e um grande desafio para o entendimento da dinâmica econômica e política do País.

Todos os maiores bancos estão envolvidos na direção dos órgãos de representação de classe do setor financeiro, oito deles, na própria FEBRABAN. É expressiva a participação dos bancos ou grupos financeiros internacionais na direção das entidades de classe tanto no Brasil como em outros países latinoamericanos. Atuando de forma simultânea nessas associações, criam um enorme potencial para, entre outros aspectos, realizar ações coordenadas e promover troca de informações. Praticamente para a metade dos casos examinados, o envolvimento com o processo político e as políticas governamentais manifesta-se na privatização dos bancos estatais, no financiamento das campanhas eleitorais e na atuação em órgãos político-ideológicos que articulam políticas públicas e ações políticas de orientação neoliberal. Em menor número, mas não por isso menos importante, tal influência consolida-se no trânsito para o comando estratégico do Banco Central.

A análise realizada, que delimitou o universo do sistema financeiro aos dez maiores bancos privados, levou em consideração um conjunto de características e indicadores que permitem avaliar melhor a questão do poder das instituições financeiras no País, como lócus de acumulação e concentração de riqueza e como presença e poder sociopolítico numa sociedade marcada por profundas desigualdades econômicas, sociais e políticas. 
Sociologias, Porto Alegre, ano 9, no 18, jul./dez. 2007, p. 100-125

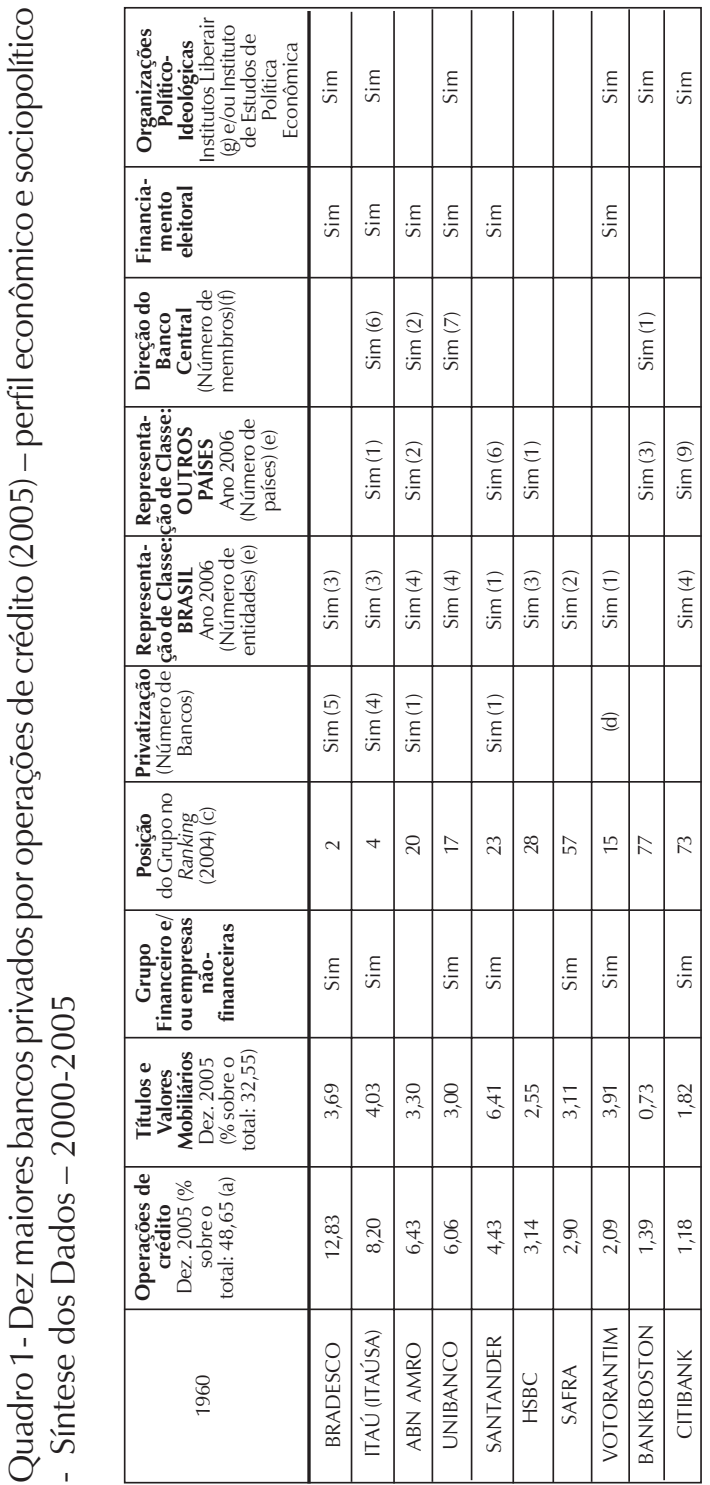

난.

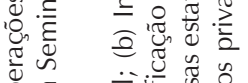

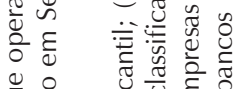

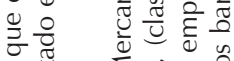

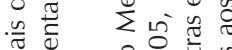

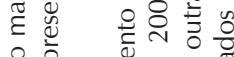

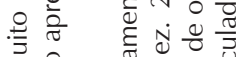

है $\frac{O}{x} \quad \frac{\pi}{0} \frac{0}{0}$ Uี

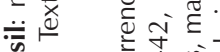

๑.

능

๘.

एँ

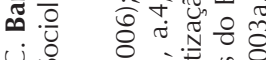

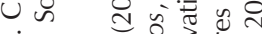

सह च

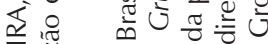

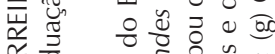

剀

丩.

ن

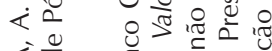

⿺辶寸

岂気

र

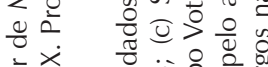

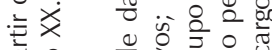

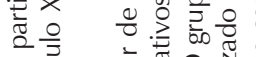

政

㐫

䒕응

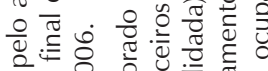

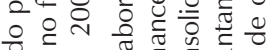

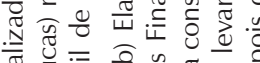

䒕

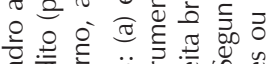

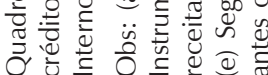




\section{Referências}

ALCORTA, L. El nuevo capital financiero: grupos financieros y ganancias sistémicas en el Perú. Lima: Fundación Friedrich Ebert, 1992.

ARAÚJO, E. R. W. A liderança de qualidade, de mercado e excelência operacional da Companhia Brasileira de Metalurgia e Mineração: o caso do prometo de redução de finos para o departamento de britagem. 2003. Monografía (Engenharia de Produção) - Universidade Federal de Ouro Preto, Ouro Preto, 2003.

AZPIAZU, D.; BASUALDO, E.; KHAVISSE, M. EI nuevo poder económico en la Argentina de los años 80. 3. ed. Buenos Aires: Editorial Legasa, 1989.

BANCO CENTRAL DO BRASIL. Sistema Financeiro Nacional, Informações cadastrais e contábeis, Informações Contábeis, $\mathbf{5 0}$ maiores bancos. Disponível em: <http://www.bcb.gov.br/fis/top50/port/default>. Acesso em: 20 jul. 2006.

BASUALDO, E. Concentración y centralización del capital en la Argentina durante la década del noventa. Buenos Aires: Editorial Universidad de Quilmes, 2002.

CARVALHO, C. E. Ocultamento e mistificação nas relações do Banco Central com os bancos: notas sobre a experiência brasileira. Política \& Sociedade: Revista de Sociologia Política, Florianópolis, v. 1, n. 6, p. 195-220, 2005.

CARVALHO, C. E. et al. Desnacionalização do setor bancário e financiamento das empresas: a experiência brasileira recente. Textos para Discussão, Brasília, IPEA, n. 882, p. 1-75, maio 2002.

CHESNAIS, F. A "nova economia": uma conjuntura própria à potência econômica estadunidense. In: CHESNAIS, F. et al. Uma nova fase do capitalismo? São Paulo: Xamã, 2003. p. 43-70.

CINTRA, M. A. M. A reestruturação patrimonial do sistema bancário brasileiro e os ciclos de crédito entre 1995 e 2005. Política Econômica em Foco, Campinas, UNICAMP, Boletim n.7, p. 292-318, abr./nov. 2006. Disponível em: < http:// www.eco.unicamp.br/asp-scripts/boletim_cecon/boletim_cecon7.asp >. Acesso em: 30 maio 2006.

CINTRA, M. A. M.; CASTRO, E. M. M. de. A tendência à dolarização dos países latino-americanos. Novos Estudos, São Paulo, n. 60, p. 27-42, jul. 2001. 
COMIN, A.; OLIVEIRA, F. de; SARAIVA, F.; LINO, H. Crise e concentração: quem é quem na indústria de São Paulo. Novos Estudos Cebrap, n. 39, p. 149-171, jul. 1994.

COSTA, F. N. da. Origem do capital bancário no Brasil: o caso RUBI. Texto para Discussão, IE/UNICAMP, n. 106, março 2002.

DRUCK, G. et al. Bancário: um emprego de múltiplos riscos. Cadernos CRH, Salvador, n. 37, p. 217-233, jul.-dez. 2002.

FERREIRA, A. C.; ALVIM, V. (Org.). A trama da privatização: a reestruturação neoliberal do Estado. Florianópolis: Insular, 2001.

. Os donos da dívida. Um enfoque sociopolítico da dívida pública interna durante o governo FHC. 2005. 111 f. Dissertação (Mestrado em Sociologia Política) - Programa de Pós-Graduação em Sociologia Política, Florianópolis, Universidade Federal de Santa Catarina, 2005.

FREITAS, M. C. P. de; PRATES, D. M. A abertura financeira no governo FHC: impactos e conseqüências. Economia e Sociedade, Campinas, UNICAMP, n. 17, p. 81-111, dez. 2001.

GONÇALVES, R. Grupos econômicos: uma análise conceitual e teórica. Revista Brasileira de Economia, Rio de Janeiro, v. 4, n. 4, p. 491-518, out./dez. 1991.

GRANOVETTER, M. Business groups. In: SMELSER, N. J.; SWEDBERG, R. (Ed.). The handbook of Economic Sociology. Princeton, N.J.: Princeton University Press, 1994. p. 453-475.

GRISCI, C. L. I. Tempos modernos, tempos mutantes: produção de subjetividade na reestruturação do trabalho bancário. SOCIUS Working Papers, Lisboa, Universidade Técnica de Lisboa, n. 3, p. 1-19, 2002.

GROS, D. B. Institutos liberais e o neoliberalismo no Brasil da Nova República. Porto Alegre: Fundação de Economia e Estatística Siegfried Emanuel Heuser, 2003a. (Teses FEE, n.6).

. Organizações empresariais e ação política no Brasil a partir dos anos 80. Civitas: Revista de Ciências Sociais, Porto Alegre, v. 3, n. 2, p. 273-300, jul./dez. 2003 b. 
GRÜN, R. A evolução recente do espaço financeiro no Brasil e alguns reflexos na cena política. DADOS - Revista de Ciências Sociais, Rio de Janeiro, v. 47, n.1, p.5$47,2004$.

JACOB, C. A. Crédito bancário no Brasil: uma interpretação heterodoxa.. 160 f. Tese (Doutorado em Economia) - Instituto de Economia, UNICAMP, Campinas, 2003.

JINKINGS, N. Trabalho e resistência na "fonte misteriosa": os bancários no mundo da eletrônica e do dinheiro. Campinas: Editora da Unicamp, 2002.

JUNCKES, I. J. O sindicalismo novo dos bancários na reestruturação financeira dos anos noventa no Brasil. 2004. Tese (Doutorado em Sociologia Política) Programa de Pós-Graduação em Sociologia Política, Universidade Federal de Santa Catarina, Florianópolis, 2004.

LARANGEIRA, S.; FERREIRA, V. Excluídos e beneficiários dos processos de reestruturação: estudo comparativo da regulação do emprego no sector bancário em Portugal e no Brasil. Revista Crítica de Ciências Sociais, Lisboa, n. 57/58, p. 53- 85, jun./nov. 2000.

LEILA, C. D. Por que os bancos são o melhor negócio no país? In: ALBUQUERQUE, E.S. de. Que país é esse? Pensando o Brasil contemporâneo. São Paulo: Globo, 2005. p. 27-62.

MAKLER, H. M.; NESS, W. L. Jr. How financial intermediation challenges national sovereignty in emerging markets. The Quarterly Review of Economics and Finance, n. 42 , p. $827-851,2002$.

MINELLA, A. C. Globalização financeira e as associações de bancos na América Latina. Civitas - Revista de Ciências Sociais, Porto Alegre, v. 3, n. 2, p. 245-272, jul./dez. 2003.

. Grupos financeiros e associações de classe do sistema financeiro. In: MENDONÇA, S. R. de. (Org.). O Estado brasileiro: agências e agentes. Niterói: EdUFF; Vício de Leitura, 2005. p.159-178.

MINELLA, A. C.; FERREIRA, A. C. Bancos no Brasil: muito mais que operações de crédito (poucas) no final do Século XX. Florianópolis: Programa de Pós-Graduação em Sociologia Política da UFSC, abr. 2006. Seminário Interno. 
MINTZ, B.; SCHWARTZ, M. The power structure of American business. Chicago: University of Chicago Press, 1985.

MIRANDA, E. Federação Brasileira de Bancos: uma análise sociopolítica do período 1994-2001. 2004. Dissertação (Mestrado em Sociologia Política) - Programa de Pós-Graduação em Sociologia Política, Universidade Federal de Santa Catarina, Florianópolis, 2004.

MORAIS, L. A evolução institucional do Banco Central e as mudanças da política monetária no Brasil no período 1964-1998. Política \& Sociedade: Revista de Sociologia Política, Florianópolis, v.1, n.6, p. 221-253, 2005.

NEIVA, P. Estrutura de poder e processo decisório na regulamentação do sistema financeiro nacional: uma proposta de análise sob a perspectiva da não-decisão. 1995. Dissertação (Mestrado) - Instituto de Ciência Política e Relações Internacionais, Universidade de Brasília, Brasília, 1995.

NOVELLI, J. M. N. Instituições, política e idéias econômicas: o caso do Banco Central do Brasil (1965-1998). São Paulo: Annablume; Fapesp, 2001.

OLIVIERI, C. A política de nomeação do alto escalão do Banco Central do Brasil (1985-2000). 2001. 91 f. Dissertação (Mestrado em Ciência Política) - São Paulo: Universidade de São Paulo, 2001.

ORTIZ, R.. Mundialização e cultura. 2. ed. São Paulo: Brasiliense, 1994.

PASSOS, D. D. dos. A internacionalização do setor bancário no Brasil após o Plano Real: divergências de interesses dos banqueiros com a ação do Estado e mudanças nas negociações com os trabalhadores bancários. 2001. Dissertação (Mestrado em Sociologia) - Universidade Federal do Paraná, Curitiba, 2001.

PAULA, L. F.; MARQUES, M. B. L. Tendências recentes da consolidação bancária no mundo e no Brasil. In: ENCONTRO NACIONAL DE ECONOMIA POLÍTICA, SOCIEDADE BRASILEIRA DE ECONOMIA POLÍTICA, IX, Uberlândia, 2004. Anais... Uberlândia: Universidade Federal de Uberlândia, 2004. Disponível em: < http:// www.sep.org.br/eventos.asp?evento=s_nove $>$. Acesso em: 4 nov. 2004.

PORTUGAL JR., J. G. (Org.). Grupos econômicos: expressão institucional da unidade empresarial contemporânea. São Paulo: FUNDAP/IESP, 1994. (Estudos de Economia do Setor Público, 2). 
RIBEIRO, A. Bancos lideram contribuições a FHC. Folha de São Paulo, São Paulo, p. 1-13, 6 de jun. 1999 .

ROCHA, F. A. S. Evolução da concentração bancária no Brasil (1994-2000). Notas Técnicas do Banco Central do Brasil, Brasília, n. 11, p. 1-42, nov. 2001.

RODRIGUES, L. Metáforas do Brasil: demissões voluntárias, crise e rupturas no Banco do Brasil. São Paulo: Annablume; Fapesp, 2004.

SALVIANO JR., C. Bancos estaduais: dos problemas crônicos ao PROES. Brasília: Banco Central do Brasil, 2004.

SCHVARZER, J. Grandes grupos económicos en Argentina. Formas de propiedad y lógicas de expansión. Revista Mexicana de Sociología, v. 57, n. 4, p. 191-210, oct./dic., 1995.

SICSÚ, J. Rumos da liberalização financeira brasileira. Revista de Economia Política, São Paulo, v. 26, n. 3, p. 364-380, jul.-set. 2006.

STOLOVICH, L. El poder económico en el MERCOSUR. Montevidéu: Centro Uruguay Independente, 1993.

. Los grupos económicos de Argentina, Brasil y Uruguay. Revista Mexicana de Sociología, v. 57, n. 4, p. 173-189, oct.-dic. 1995.

UNIBANCO. Informações trimestrais, referentes ao trimestre findo em $\mathbf{3 1}$ de março de 2002. 2002.

Relatório Anual, 2004.

VALOR GRANDES GRUPOS, ano 4, n. 4, dez., 2005.

VIDOTTO, C. A. O sistema financeiro brasileiro nos anos noventa. Um balançO das mudanças estruturais. 2002. Tese (Doutorado em Economia) - Instituto de Economia, UNICAMP, Campinas, 2002. 


\section{Resumo}

O trabalho analisa elementos do poder das instituições financeiras, destacando o controle sobre o fluxo de capitais - caracterizado como hegemonia financeira -, a constituição dos grupos econômicos ou financeiros, a estrutura de representação dos interesses de classe do setor e a participação deste no processo político e nos aparatos de decisão do Estado. Considerando a reestruturação financeira ocorrida no Brasil na década de 1990, o trabalho traça um perfil dos dez maiores bancos privados a partir de indicadores econômicos e sociopolíticos selecionados. Para além de sua posição como meros intermediários financeiros, identifica-se em que medida esses bancos configuram-se como grupos econômicos e, especialmente, como unidades de articulação mais ampla, que se revela em conexões com o Estado e com a própria organização e atuação de classe nos âmbitos corporativo e político.

Palavras-chave: sistema financeiro, concentração bancária, grupos financeiros, hegemonia financeira, representação de classe.

Recebido: 30/01/2007

Aceite final: 10/06/07 